\title{
CC-CV Controlled Fast Charging Using Type-2 Fuzzy for Lithium-Ion Battery
}

\author{
Ahmad Zidan Falih \\ Department of Electrical Engineering \\ Politeknik Elektronika Negeri Surabaya \\ Surabaya, Indonesia \\ ahmadzidanfalih@pe.student.pens.ac.id
}

\author{
Mohammad Zaenal Efendi \\ Department of Electrical Engineering \\ Politeknik Elektronika Negeri Surabaya \\ Surabaya, Indonesia \\ zen@pens.ac.id
}

\author{
Farid Dwi Murdianto \\ Department of Electrical Engineering \\ Politeknik Elektronika Negeri Surabaya \\ Surabaya, Indonesia \\ farid@pens.ac.id
}

\begin{abstract}
Energy dependency is increasing along with the increase in population growth rate, while fossil energy is decreasing. Alternative energy such as solar energy is one solution to provide renewable energy, but solar energy cannot provide an intense supply of energy. Therefore, the equipment needs energy storage. The battery has an important role in energy storage with the performance of the battery that needs attention. The method and type of battery used must be considered to maintain battery lifetime and reduce overcharging. The purpose of this research is to understand the process of fast charging using the $\mathrm{CC}-\mathrm{CV}$ (Constant Current Constant Voltage) method on Lithium-Ion batteries which is expected to reduce battery overcharging. In this method, the current is maintained constant until certain conditions then followed by constant voltage to prevent overcharging. The voltage from the solar panel is very high, voltage reduction is needed as the charging voltage for the battery. The DC-DC Converter used is Buck Converter which is given Type-2 Fuzzy algorithm to maintain current of 10 Ampere during CC conditions and voltage of 14.4 Volt during $\mathrm{CV}$ condition that switch from CC condition to CV conditions at SoC 99.25\%.
\end{abstract}

Keywords-battery charging, buck converter, CC-CV, lithiumion, type-2 fuzzy.

\section{INTRODUCTION}

Energy is an essential requirement and cannot be separated from human life. With the development of technology globally, the energy demand also increases, especially electrical energy. The energy demand will continue to increase along with the increase in population growth. Most of the energy consumed is non-renewable fossil energy [1]. Excessive use of non-renewable energy can lead to an energy crisis, so that the use of renewable energy is urgently needed in future life. Various approach have been taken to determine the potential of energy sources developed in Indonesia by utilizing solar energy as alternative energy utilization. However, solar energy cannot provide its energy supply intensely because it can only be obtained during the daytime. So it requires equipment that can be used as energy storage to provide an energy supply that can be utilized at any time. At this time, the most widely used energy storage is batteries. So that electrical energy converted by the solar panel can be stored in batteries [2].

As it is well known that the use of renewable energy requires equipment as energy storage, thus a fast charging of the battery from solar panels which can regulate the voltage drop from solar panels to battery and drain the maximum current from the solar panels is made in this research. The output voltage generated by the solar panel is very high for the battery charging process, so it is necessary to reduce the voltage [3].

In this $\mathrm{CC}-\mathrm{CV}$ method, the current is maintained constant until certain conditions, followed by a constant voltage to prevent overcharging. When the voltage is constant, the current gradually decreases according to the battery conditions [4]. In order for the output of the converter to be stable, the Type-2 Fuzzy algorithm is used to maintain the current and voltage constant. Type-2 Fuzzy is a form of development of the Fuzzy logic Control (FLC) method. The input of the FLC method is in the form of error and delta error with output of duty cycle that will be used to adjust the PWM (Pulse Wide Modulation).

This research aims to determine the process of fast charging CC-CV process on lithium-ion battery using Type-2 Fuzzy. The type of converter used to reduce the voltage is the buck converter. The output current of the buck converter is 10 Ampere and the voltage is 14.4 Volt. The Type-2 Fuzzy algorithm is employed to maintain the voltage and current constant as designed. This method will be used as a parameter for charging a 10 Ah lithium-ion battery that takes about 1 hour until the battery is full. To support fast charging, several conditions are needed, such as the value of current used for charging the battery and also a battery that can handle large currents, therefore the lithium-ion battery is used. Lithium-Ion battery is designed to reach most of its capabilities and can accept large currents. So that the effectiveness of charging can be as desired [5].

\section{METHODS}

The methods used in this research will be explained at the following below:

\section{A. System Design}

This study aims to determine the fast-charging process using the CC-CV method with a voltage source from solar panels. Figure 1 shows the system design.

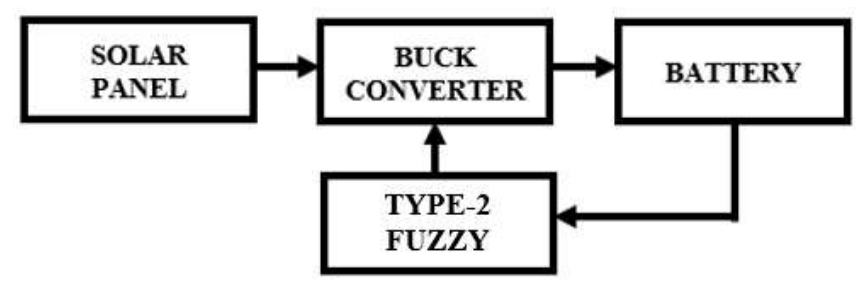

Fig. 1. System design.

From the block diagram of the system in Fig. 1, shows the source used is solar energy which is converted into electrical 
energy using solar panel, that energy is then stored in the battery. The buck converter is used for charging the battery so that the battery will be full quickly with the CC-CV method to reduce overcharge. The Type-2 Fuzzy algorithm is used in this research to maintain the output current and voltage to become constant.

\section{B. System modelling}

\section{1) Buck Converter}

Buck converter is a DC-DC converter topology that is used to reduce DC voltages. The working principle of this circuit is by switching control. The main components of the buck converter topology are an active switch (MOSFET), a passive switch (diode), a capacitor, and an inductor as the output filter. Illustration of the buck converter is shown in Fig. 2 [6].

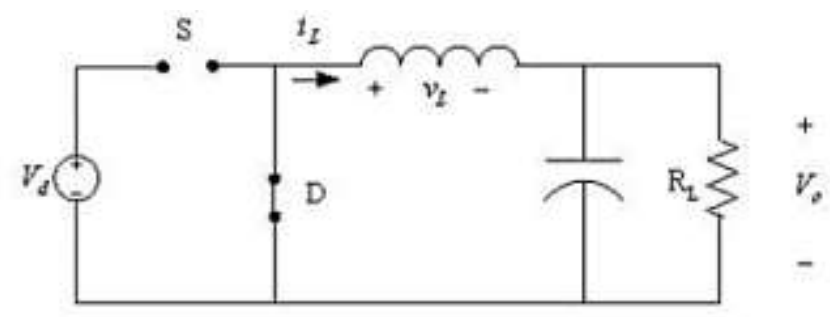

Fig. 2. Buck converter.

To have the pure DC output of the circuit mentioned in Fig. 3, the inductor and capacitor act as a low pass filter which is installed after the electronic switch/MOSFET. This diode is essential for ensuring the desired flow of inductor current when the electronic switch is opened. The diode must be in reverse bias when the switch is closed [6].

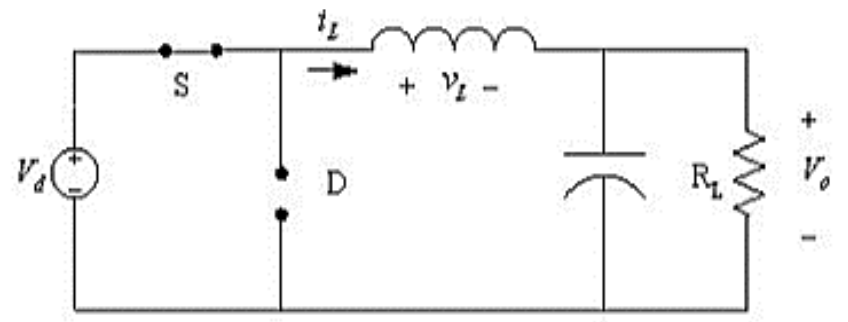

Fig. 3. Buck converter on state.

Fig. 3 illustrates when the switch is closed, the diode is in reverse so that the input signal goes to the inductor and energy storage occurs. From the picture above, the equation can be written as follows:

$$
\begin{aligned}
& V L=V s-V o=L \frac{d i L}{d t} \\
& \frac{d i L}{d t}=\frac{(V s-V o)}{L} \\
& \frac{d i L}{d t}=\frac{\Delta i L}{\Delta t}=\frac{\Delta i L}{D T}=\frac{(V s-V o)}{L} \\
& \Delta i L c l o s e d=\frac{(V s-V o)}{L} D T
\end{aligned}
$$

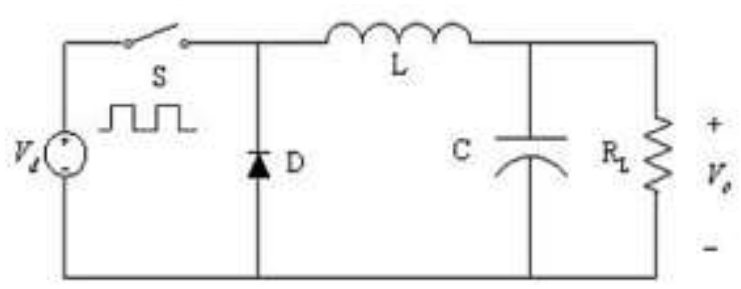

Fig. 4. Buck converter off state.
Fig. 4 illustrates when the switch is opened, the diode becomes forward biased so that there is a flow of voltage through the capacitor. So that from the picture above, an equation can be written as follows:

$$
\begin{aligned}
& V L=-V o=L \frac{d i L}{d t} \\
& \frac{d i L}{d t}=\frac{-V o}{L} \\
& \frac{d i L}{d t}=\frac{\Delta i L}{\Delta t}=\frac{\Delta i L}{(1-D) T}=-\frac{V o}{L} \\
& \Delta i L o p e n e d=-\frac{V o}{L}(1-D) T
\end{aligned}
$$

The parameter values used in the buck converter system with a frequency of $100000 \mathrm{~Hz}$ to reduce the inductor value. By using high frequency, the output wave will be smoother [7]. The specifications are as follows: $\mathrm{V}_{\text {in }}=18 \mathrm{~V} ; \mathrm{V}_{\text {out }}=$ $14.4 \mathrm{~V} ; \mathrm{I}_{\text {out }}=10 \mathrm{~A} ; \mathrm{R}=1.44 \Omega ; \mathrm{L}=14.4 u \mathrm{H} ; \mathrm{C}=$ $173.6 u \mathrm{~F} ; \mathrm{f}=100000 \mathrm{~Hz}$

1. Duty cycle

$$
D=\frac{V_{\text {out }}}{V_{\text {in }}}=\frac{14.4}{18}=0.8
$$

2. Rated Load Current

$$
R=\frac{V_{\text {out }}}{I_{\text {out }}}=\frac{14.4}{10}=1.44 \Omega
$$

3. Inductor value

$$
\begin{aligned}
& \text { Current Ripple }=20 \% \\
& \begin{aligned}
& I_{L} \text { (avg) }=I_{\text {out }}=I_{R} \\
& \begin{aligned}
\Delta I_{L} & =20 \% \times I_{L} \\
& =0.2 \times 10 \\
& =2 \mathrm{~A}
\end{aligned}
\end{aligned} \\
& \begin{aligned}
L & =\frac{V_{\text {out }} \times(1-D)}{\Delta I_{L} \times f}=\frac{14.4 \times(1-0.8)}{2 \times 100000}
\end{aligned}
\end{aligned}
$$

4. Maximum Inductor Current

$$
\begin{aligned}
& I_{\max }=I_{L}+\frac{\Delta I_{L}}{2} \\
& I_{\max }=10+\frac{2}{2}=11 \mathrm{~A}
\end{aligned}
$$

5. Capacitor Value

$$
\begin{aligned}
r= & \frac{\Delta V_{\text {out }}}{V_{\text {out }}}=0.1 \% \\
C= & \frac{1-D}{8 L r f 2}=\frac{1-D}{8 L r f^{2}}=\frac{1-0.8}{8 \times 14.4 \times 10^{-6} \times 0.001 \times 100000^{2}}= \\
& 173.6 u F
\end{aligned}
$$

\section{2) Lithium-Ion Battery}

The lithium-ion battery has many advantages, unlike other types of batteries. The advantages include that lithium-ion batteries have an excessive power density and power. This allows them to be the best preference in utilities that require a lot of energy [8]. The power of lithium-ion batteries can preserve the quantity of energy that last up to 3 instances more than $\mathrm{Ni}-\mathrm{Cd}$ batteries with identical quantity and weight. However, the lithium-ion battery has a low self-discharge rate when not in use [9].

Lithium-ion batteries are members of the rechargeable battery family. Lithium-ion batteries use a dry polymer electrolyte shaped like a thin filament plastic layer. This film layer is arranged in a layer between the anode and cathode 
resulting in ion exchange. By this method the lithium-ion batteries can be made in a variety of shapes and sizes. Lithium-ion batteries have advantages such as being very lightweight, designed for more durable drop usage, and because the nature of this battery is non-removable and this battery has a better level of safety in high temperature conditions. This research used a 12 V/10 Ah battery with the rate of fast charging $1 \mathrm{C}[10]$.

\section{3) CC-CV Method}

Several methods can be used to control the battery's charging process. One of the most popular is the CV (Constant Voltage) method, which maintains a constant voltage until the battery is at full capacity, but this method takes a long time to charge the battery. CC (Constant Current) method provides a constant current until the battery is full, but this method can cause overcharging. Another method used is CC-CV (Constant Current Constant Voltage). This method is safer because it does not cause overcharging, because when moving from $\mathrm{CC}$ to $\mathrm{CV}$, the current will decrease. CC-CV method supports fast charging by providing current of $1 \mathrm{C}$ to shorten the charging time [11].

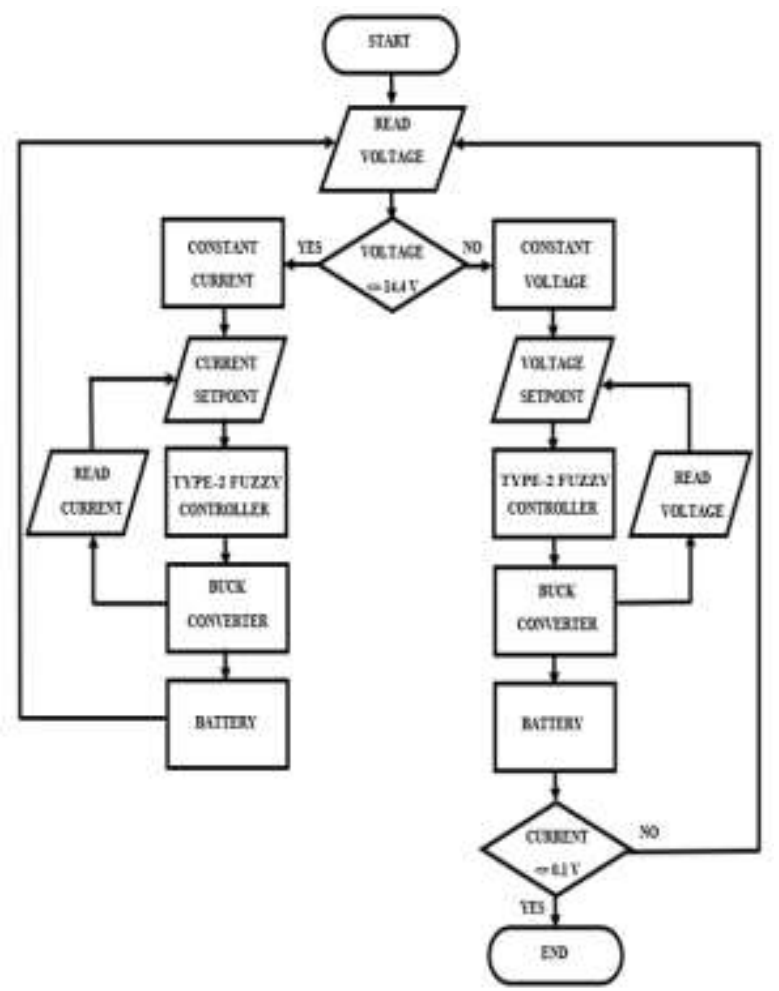

Fig. 5. Flowchart CC-CV method.

The process of the CC-CV method shows in Fig. 5, a constant current followed by constant voltage until the battery is full to reduce overcharge and maintain a lifetime battery.

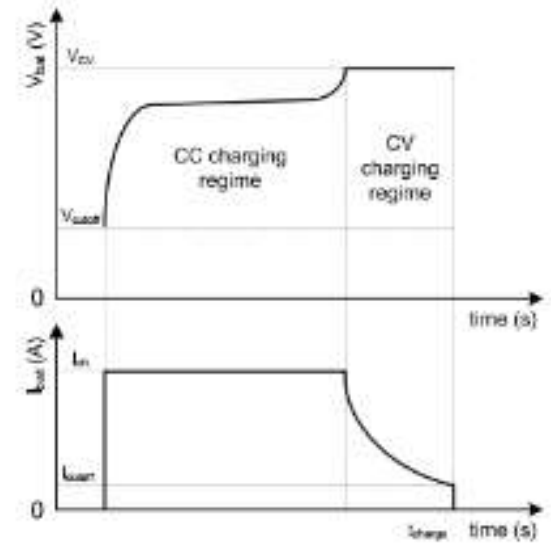

Fig. 6. CC-CV method.

Fig. 6 shows CC-CV technique is divided into two conditions. The first condition is that the current is maintained constant, while the voltage will increase up to certain SOC. Then proceed with a condition where the voltage is maintained constant until the battery is full, in this condition the current will decrease.

\section{4) Type-2 Fuzzy Algorithm}

Type-2 Fuzzy algorithm is the development of the Fuzzy logic Control (FLC) method. The FLC method is a control system scheme that uses the concept of fuzzy set theory in its design. There are three stages in the FLC method, namely fuzzification, inference mechanism and defuzzification. Type2 Fuzzy Method has advantages over the FLC method in determining appropriate membership functions, and a modeling variety of different data [12]. The following is Structure Type-2 Fuzzy logic system is shown in Fig. 7.

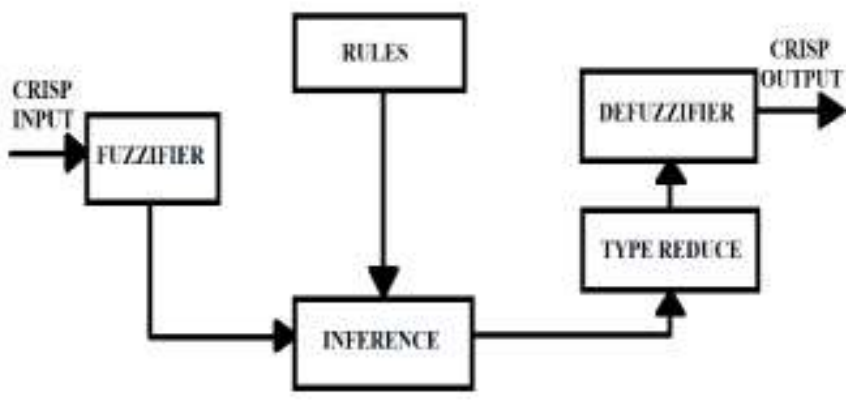

Fig. 7. Structure type-2 fuzzy.

Type-2 Fuzzy algorithm consists of four main processes, namely fuzzification, decision making (inference), reduction, and defuzzification. The structure is almost the same as the Fuzzy Type- 1 structure. The difference is that after getting the result of the inference output, it is followed by reducing to change the set from Type-2 Fuzzy to the Fuzzy Type-1 set. Thus, Fuzzy Type-1 is defuzzified to be a firm value on the Type-2 Fuzzy [13]. 


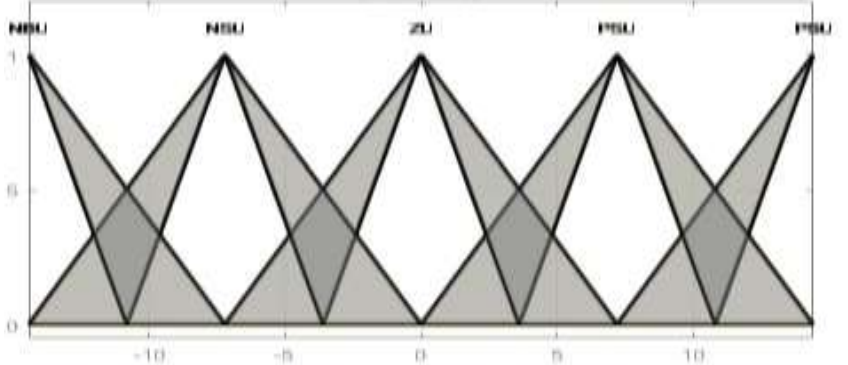

(a)

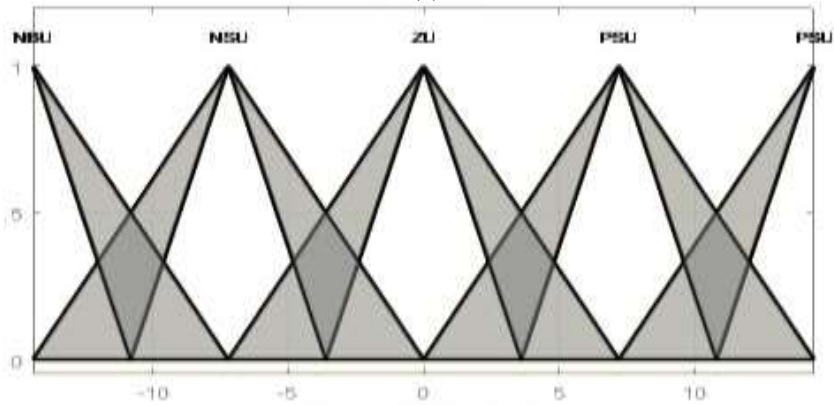

(b)

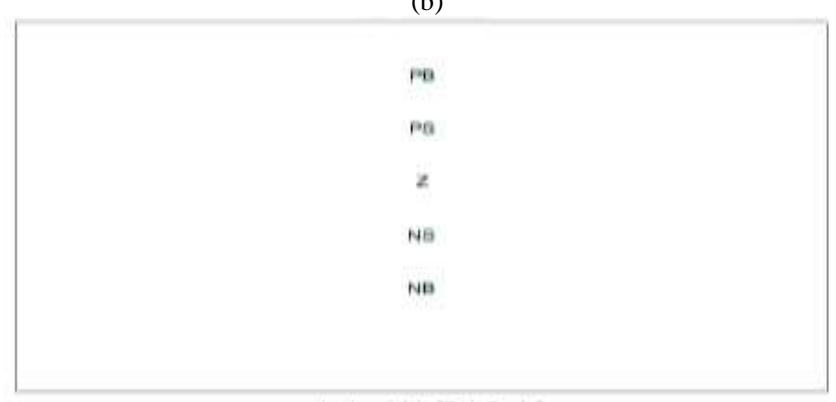

(c)

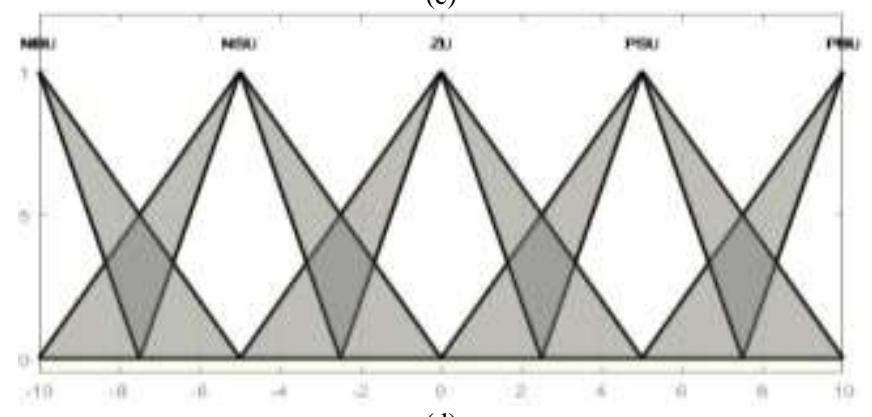

(d)

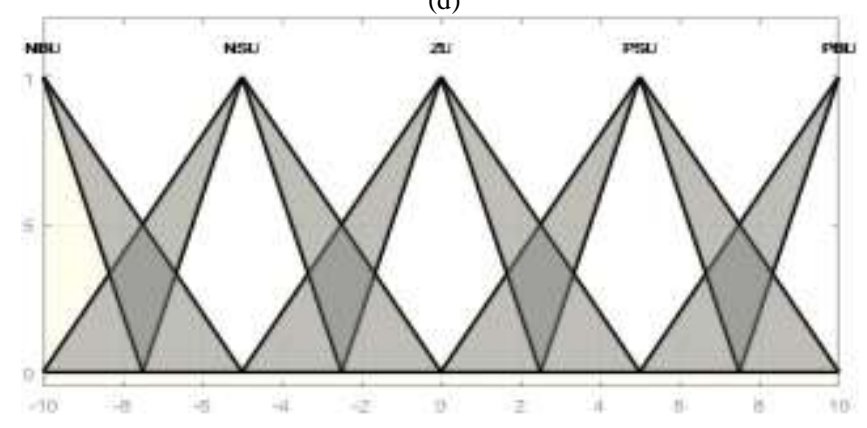

(e)

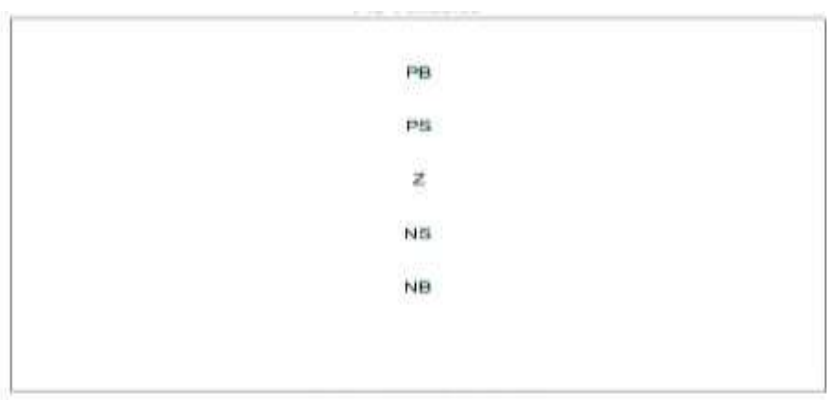

(f)

Fig. 8. Membership error CV (a), Membership delta error (b), Output variable CV (c), Membership error CC (d), Membership delta error CC (e), Output variable CC (f)

Membership Function in Type-2 Fuzzy is a modification of Fuzzy Type-1. In Type-2 Fuzzy the membership function used consists of upper and lower limits, namely Upper MF and Lower MF [14]. Five membership functions, namely Big Negative (NB), Small Negative (NS), Zero (Z), Small Positive (PS), and Big Positive (PB).

TABLE I. RULE BASE TYPE-2 FUZZY

\begin{tabular}{|c|c|c|c|c|c|c|}
\hline \multicolumn{2}{|c|}{$\Delta \boldsymbol{u}(\boldsymbol{k})$} & \multicolumn{5}{|c|}{$\boldsymbol{\Delta E}(\boldsymbol{k})$} \\
\cline { 2 - 7 } & NB & NS & ZE & PS & PB \\
\hline \multirow{4}{*}{$\boldsymbol{E}(\boldsymbol{k})$} & NB & PB & PS & NB & NB & NB \\
\cline { 2 - 7 } & NS & ZE & ZE & NS & NS & NS \\
\cline { 2 - 7 } & ZE & NS & ZE & ZE & ZE & PS \\
\cline { 2 - 7 } & PS & PS & PS & PS & ZE & ZE \\
\cline { 2 - 7 } & PB & PB & PB & PB & NS & NS \\
\hline
\end{tabular}

Type-2 Fuzzy has twenty-five rules, namely the membership function of the error variable and the delta error. The twenty-five rules are a combination of the five forms of the input variable membership function and the delta error. The resulting rules are shown in Table 1. For type reduction of Type-2 Fuzzy use Karnil and Mendel method and Sugeno method for defuzzification [15].

\section{SIMULATION RESULTS AND DISCUSSION}

After taking the actual data, the current and voltage parameters are obtained. These are used as a fast charging parameters of a lithium-ion battery using Type-2 Fuzzy algorithm to maintain a constant current and a constant voltage

\section{A. The Test Results of Type-2 Fuzzy}

Testing of Type-2 Fuzzy constant current constant voltage when charging is carried out to determine whether the system can maintain a constant current and a constant voltage according to the design and compare it when it is without control and control. Simulation Testing Type-2 Fuzzy constant current constant voltage is carried out under two conditions, namely constant current and constant voltage. Two conditions will be compared to determine the effect of the Type-2 Fuzzy control on the system. 


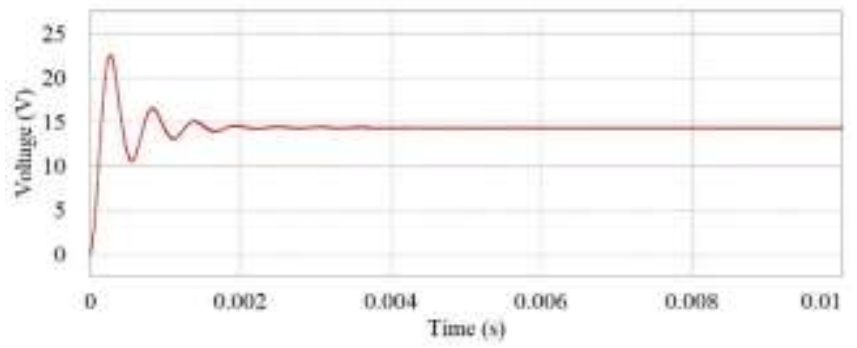

Fig. 9. Open loop voltage response.

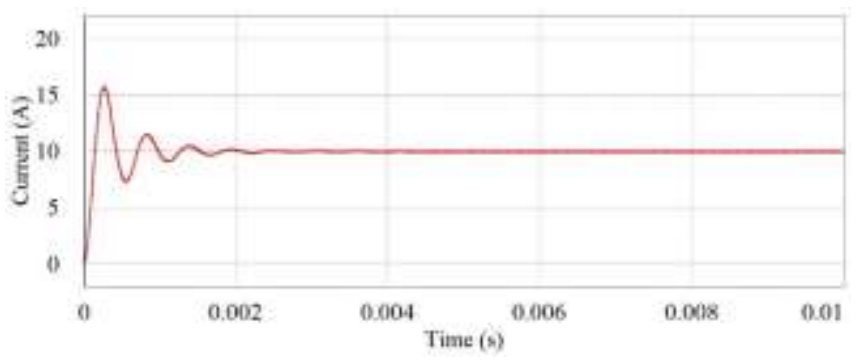

Fig. 10. Open loop current response.

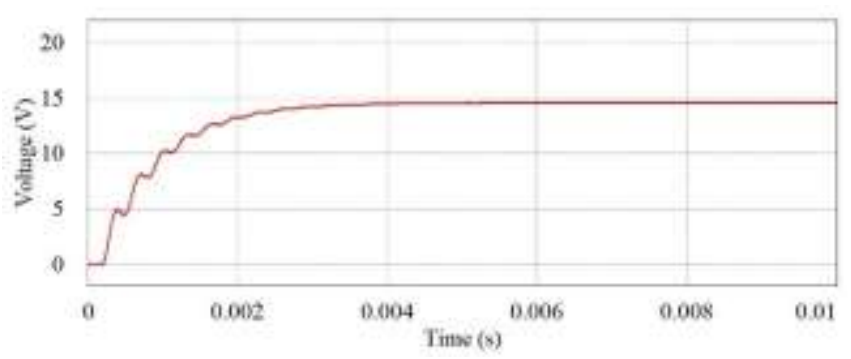

Fig. 11. Close loop voltage response.

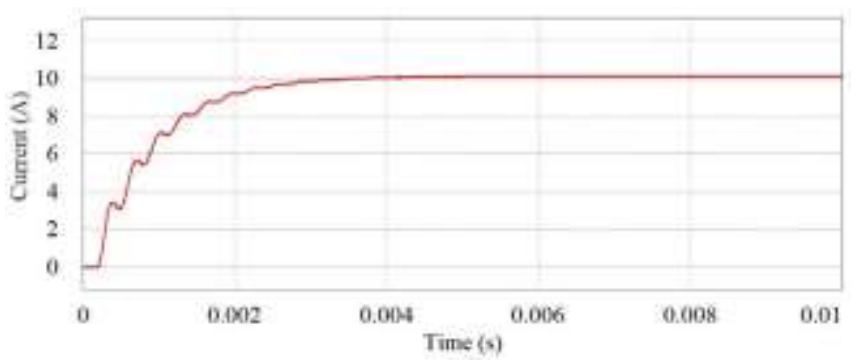

Fig. 12. Close loop current response.

Fig. 11. and Fig. 12. show the results of the close loop response waveform that can eliminate the occurrence of overshoot on the open loop waveform in Fig. 9 and Fig. 10. From the result of the Type-2 Fuzzy control test, which is carried out by varying the load to determine the response of the Type-2 Fuzzy. The error comparison between the results of the open loop and closed loop testing result will be presented in the form of tables as shown in Table 2. and Table 3.
TABLE II.

COMPARISON OF OPEN LOOP AND CLOSED LOOP $\mathrm{CC}$

\begin{tabular}{|c|c|c|c|c|c|}
\hline \multirow{2}{*}{$\begin{array}{c}\text { Load } \\
(\Omega)\end{array}$} & \multirow{2}{*}{$\begin{array}{c}\text { Set } \\
\text { Point } \\
(\mathrm{V})\end{array}$} & \multicolumn{2}{|c|}{ Current (A) } & \multicolumn{2}{|c|}{ Error $(\%)$} \\
\hline & & $\begin{array}{l}\text { Open } \\
\text { Loop }\end{array}$ & $\begin{array}{c}\text { Closed } \\
\text { Loop }\end{array}$ & $\begin{array}{l}\text { Open } \\
\text { Loop }\end{array}$ & $\begin{array}{c}\text { Closed } \\
\text { Loop }\end{array}$ \\
\hline 1 & \multirow{4}{*}{10} & 14 & 9.78 & 40 & 2.2 \\
\hline 1.5 & & 9.3 & 9.9 & 7 & 1 \\
\hline 2 & & 7 & 8.7 & 30 & 13 \\
\hline 2.5 & & 5.6 & 7 & 44 & 30 \\
\hline
\end{tabular}

TABLE III. COMPARISON OPEN LOOP AND CLOSED LOOP CV

\begin{tabular}{|c|c|c|c|c|c|}
\hline \multirow{2}{*}{$\begin{array}{c}\text { Load } \\
(\Omega)\end{array}$} & \multirow{2}{*}{$\begin{array}{l}\text { Set } \\
\text { Point } \\
\text { (A) }\end{array}$} & \multicolumn{2}{|c|}{ Voltage (V) } & \multicolumn{2}{|c|}{ Error $(\%)$} \\
\hline & & $\begin{array}{l}\text { Open } \\
\text { Loop }\end{array}$ & $\begin{array}{c}\text { Closed } \\
\text { Loop }\end{array}$ & $\begin{array}{l}\text { Open } \\
\text { Loop }\end{array}$ & $\begin{array}{c}\text { Closed } \\
\text { Loop }\end{array}$ \\
\hline 1 & \multirow{4}{*}{14.4} & 13.56 & 14.21 & 5.8 & 1.3 \\
\hline 1.5 & & 13.62 & 14.44 & 5.4 & 0.83 \\
\hline 2 & & 13.69 & 14.62 & 4.9 & 1.52 \\
\hline 2.5 & & 13.71 & 14.87 & 4.7 & 3.2 \\
\hline
\end{tabular}

Table 2. and Table 3. show the comparison simulation results between open loop and closed loop with load variations. Table 2. shows that the results of the $\mathrm{CC}$ simulation with variation load using Type-2 Fuzzy control get smaller errors on close loop. Table 3 . shows the result of the CV simulation using the Type-2 Fuzzy control has better results than the open loop or without using the control. This comparison proves that the use of Type-2 Fuzzy control in the system is able to maintain the output current when CC condition and maintain the output voltage when the $\mathrm{CV}$ condition.

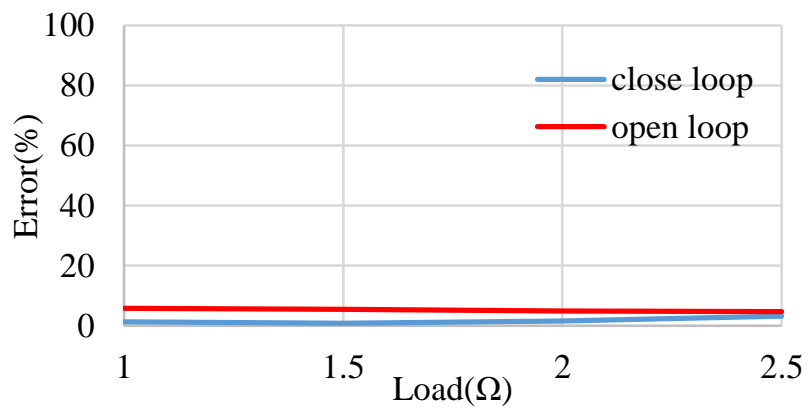

Fig. 13. CV error comparison.

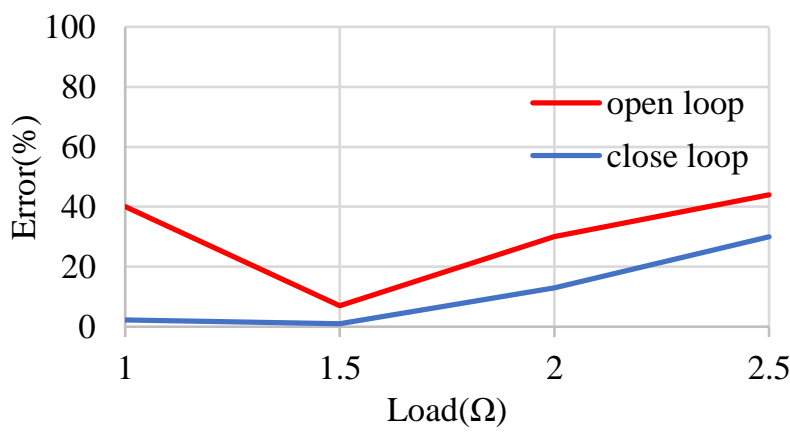

Fig. 14. CC error comparison.

Fig. 13 and Fig. 14 are graphs comparing the simulation results with Type-2 Fuzzy control and without control. In Fig. 13 , the greatest error value is obtained at a $2.5 \Omega \mathrm{load}$, which 
is $4.7 \%$ for an open loop, and $3.2 \%$ for a close loop. Fig. 14, the open loop most considerable voltage error value is $44 \%$, and the close-loop is $30 \%$ obtained at $2.5 \Omega$ load. These results show that the Type-2 Fuzzy has worked well to maintain the current and voltage constant from the set point.

\section{B. CC-CV Battery Charging}

This simulation uses a 12 Volt battery with a capacity of $10 \mathrm{Ah}$. The initial battery charging process starts from SoC 99\% to see the switch between the CC condition and the CV condition. The result of the simulation is shown in Table 4.

TABLE IV. BATTERY SOC

\begin{tabular}{|c|c|c|}
\hline SoC \% & Volt (V) & Current (A) \\
\hline 99 & 14.25 & 10.08 \\
\hline 99.5 & 14.3 & 10.06 \\
\hline 99.10 & 14.32 & 10.04 \\
\hline 99.15 & 14.37 & 10.02 \\
\hline 99.20 & 14.39 & 10 \\
\hline 99.25 & 14.4 & 9.97 \\
\hline 99.30 & 14.4 & 9.3 \\
\hline 99.35 & 14.4 & 7.6 \\
\hline 99.40 & 14.4 & 5.8 \\
\hline
\end{tabular}

Table 4 shows the initial battery charging process starts from SOC $99 \%$ to see the switch between CC conditions to $\mathrm{CV}$ conditions. The switch occurs at SOC $99.25 \%$ with voltage that has been adjusted to 14.4 Volt. Fig. 15 and Fig. 16 show the constant current to constant voltage conditions.

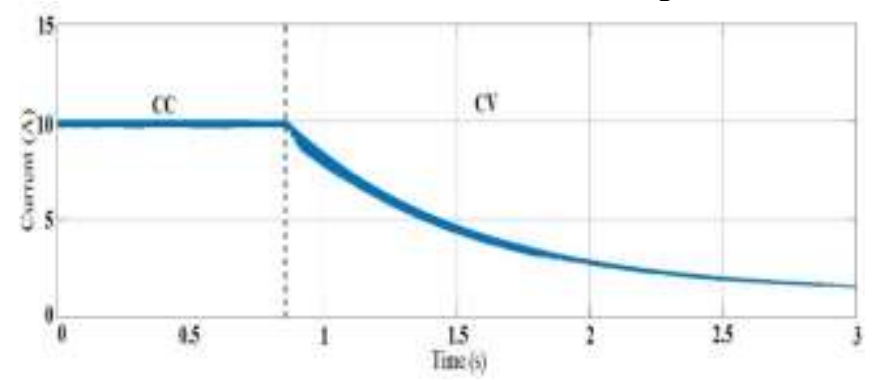

Fig. 15. Type-2 fuzzy controlled CC condition.

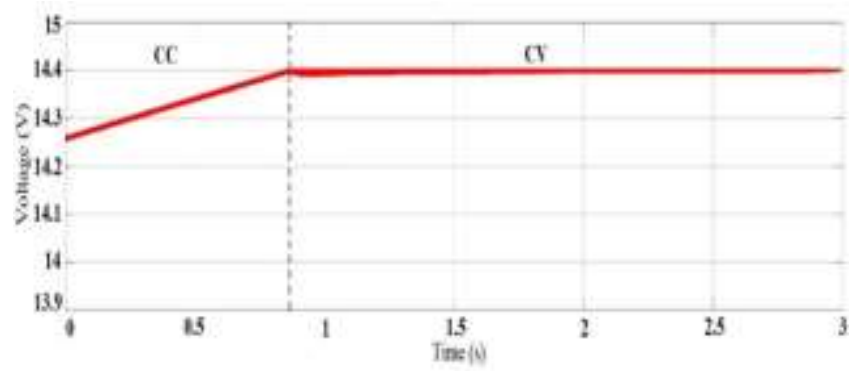

Fig. 16. Type-2 fuzzy controlled CV condition.

From the battery charging test simulation, there are two conditions, namely at the beginning of charging, the current is constant, which indicates that the charging conditions is $\mathrm{CC}$ with charging current value of 10 Ampere, and when the SOC of the battery is close to full, which is when the SOC is $99.25 \%$, the battery charging condition switches to $\mathrm{CV}$ with 14.4 Volt. The work of Type-2 Fuzzy control is that when the charging voltage has not reached the set point to switch a $\mathrm{CV}$ condition of 14.4 Volt, the duty cycle will continue tracking so that the charging current reaches/approaches the expected setting point. Furthermore, the Type-2 Fuzzy control for CC conditions will stop when the charging condition is $\mathrm{CV}$ condition.

\section{CONCLUSION}

Based on the test results of lithium-ion battery fast charging system with constant current constant voltage method using Type-2 Fuzzy control, can be concluded that buck converter using Type-2 Fuzzy controller can maintain a constant current and a constant voltage to produce a tiny error of $1 \% \mathrm{CC}$ condition and $0.83 \% \mathrm{CV}$ condition with current and voltage output in close loop condition. Application of buck converter of lithium-ion battery charger with the Constant Current Constant Voltage method work well according to the current and voltage parameters desired, with a current of 10 Ampere and a voltage of 14.4 Volt used as a fast charging parameter lithium battery with a capacity of $10 \mathrm{Ah}$ with a charge rate of $1 \mathrm{C}$. Switch from CC condition to $\mathrm{CV}$ condition at $\mathrm{SoC} 99.25 \%$.

\section{ACKNOWLEDGMENT}

The authors wish to thank the Department of Electrical Engineering of Politeknik Elektronika Negeri Surabaya that has supported this research.

\section{REFERENCES}

[1] I. Kholiq, "PEMANFAATAN ENERGI ALTERNATIF SEBAGAI ENERGI TERBARUKAN UNTUK MENDUKUNG SUBTITUSI BBM," no. 2, p. 17, 2015.

[2] B. H. Purwoto, "EFISIENSI PENGGUNAAN PANEL SURYA SEBAGAI SUMBER ENERGI ALTERNATIF," Emit. J. Tek. Elektro, vol. 18, no. 01, pp. 10-14, Mar. 2018, doi: 10.23917/emitor.v18i01.6251.

[3] N. K. Raghavendra and K. Padmavathi, "Solar Charge Controller for Lithium-Ion Battery," in 2018 IEEE International Conference on Power Electronics, Drives and Energy Systems (PEDES), Chennai, India, Dec. 2018, pp. 1-5, doi: 10.1109/PEDES.2018.8707743.

[4] H. Suryoatmojo, "Design Li-Po Battery Charger with Buck Converter under Partially CC-CV Method," in 2020 International Seminar on Intelligent Technology and Its Applications (ISITIA), Surabaya, Indonesia, Jul. 2020, pp. 101-106, doi: 10.1109/ISITIA49792.2020.9163754.

[5] A. Tomaszewska et al., "Lithium-ion battery fast charging: A review," eTransportation, vol. 1, p. 100011, Aug. 2019, doi: 10.1016/j.etran.2019.100011.

[6] T. Andromeda et al., "Design of DC Fast Charging Buck Converter for LFP Battery on Electric Car," in 2019 6th International Conference on Electric Vehicular Technology (ICEVT), Bali, Indonesia, Nov. 2019, pp. 258-262, doi: 10.1109/ICEVT48285.2019.8993974.

[7] H. Matalata and L. W. Johar, "ANALISA BUCK CONVERTER DAN BOOST CONVERTER PADA PERUBAHAN DUTY CYCLE PWM DENGAN MEMBANDINGKAN FREKUENSI PWM 1,7 Khz DAN 3,3 Khz," J. Ilm. Univ. Batanghari Jambi, vol. 18, no. 1, p. 42, Feb. 2018, doi: 10.33087/jiubj.v18i1.431.

[8] S.-C. Wang, Y.-L. Chen, Y.-H. Liu, and Y.-S. Huang, "A fast-charging pattern search for li-ion batteries with fuzzy-logic-based Taguchi method," in 2015 IEEE 10th Conference on Industrial Electronics and Applications (ICIEA), Auckland, New Zealand, Jun. 2015, pp. 855859, doi: 10.1109/ICIEA.2015.7334230.

[9] A. Al-Refai, R. AbouSleiman, and O. A. Rawashdeh, "A programmable charger for monitoring and control of multi-cell lithiumion batteries," in 2012 IEEE National Aerospace and Electronics Conference (NAECON), Dayton, OH, USA, Jul. 2012, pp. 68-74, doi: 10.1109/NAECON.2012.6531031.

[10] M. M. Hoque, M. A. Hannan, and A. Mohamed, "Optimal CC-CV charging of lithium-ion battery for charge equalization controller," in 
2016 International Conference on Advances in Electrical, Electronic and Systems Engineering (ICAEES), Putrajaya, Malaysia, Nov. 2016, pp. 610-615, doi: 10.1109/ICAEES.2016.7888119.

[11] B. Arabsalmanabadi, N. Tashakor, A. Javadi, and K. Al-Haddad, "Charging Techniques in Lithium-Ion Battery Charger: Review and New Solution," in IECON 2018 - 44th Annual Conference of the IEEE Industrial Electronics Society, Washington, DC, Oct. 2018, pp. 57315738, doi: 10.1109/IECON.2018.8591173.

[12] J. Al-Kausar and A. S. Handayani, "Perbandingan Type-1 Fuzzy Logic System (T1FLS) dan Interval Type-2 Fuzzy Logic System (IT2FLS) pada Mobile Robot," p. 5, 2018.

[13] H. Hassani and J. Zarei, "Interval Type-2 fuzzy logic controller design for the speed control of DC motors," Syst. Sci. Control Eng., vol. 3, no. 1, pp. 266-273, Jan. 2015, doi: 10.1080/21642583.2015.1013644.

[14] M. K. Asy'ari and A. Musyafa, "Design of Buck Converter Based on Interval Type-2 Fuzzy Logic Controller," in 2018 International Seminar on Intelligent Technology and Its Applications (ISITIA), Bali, Indonesia, Aug. 2018, pp. 153-156, doi: 10.1109/ISITIA.2018.8711236.

[15] I. Atacak and O. F. Bay, "A type-2 fuzzy logic controller design for buck and boost DC-DC converters," J. Intell. Manuf., vol. 23, no. 4, pp. 1023-1034, Aug. 2012, doi: 10.1007/s10845-010-0388-1. 